\title{
Recursive Male Out-migration and the Consequences at Source: A Systematic Review with Special Reference to the Left-behind Women
}

\author{
Shatabdi Saha, ${ }^{\dagger}$ Rupak Goswami ${ }^{{ }^{*}}$ and Sujit Kumar Paul'
}

\begin{abstract}
Male out-migration from rural to urban areas has amplified worldwide in the face of economic globalisation. Migration literature for long has engaged with the life of migrants at the destination and their support for the left-behind families in the form of remittances. Explicit scholastic undertaking for the left-behind women and their life experiences has started to receive attention only recently. We take stock of the existing literature to examine this social process and debate it within a women empowerment-disempowerment framework. Following a systematic review of the 'migration left-behind nexus' literature, we find a clear trend of transformation in the gender role of women everywhere, especially in the form of 'feminisation of agriculture'. This process is largely moderated by the nature and amount of remittances received at source. The resultant well-being and empowerment of women is shaped by the socio-cultural context within which migration takes place. Both positive and/or negative outcomes for left-behind women are recorded in the literature, although its choice as a conscious decision and its subsequent permanence in a society is debatable. We expect a deeper engagement of future research that takes up the migration-led women empowerment issue within the context of the general social transformation process.
\end{abstract}

Keywords: Feminisation of agriculture, Left-behind women, Male out-migration, Remittance, Women's empowerment, India

\footnotetext{
${ }^{\dagger}$ Doctoral Student, IRDM Faculty Centre, Ramakrishna Mission Vivekananda Educational and Research Institute, India, Email: dearshatabdi@gmail.com

'Assistant Professor, IRDM Faculty Centre, Ramakrishna Mission Vivekananda Educational and Research Institute, India, Email: goswamirupak@rediffmail.com

* Corresponding Author

${ }^{1}$ Department of Life Long learning \& Extension (REC), Visva-Bharati University,Bolpur, West Bengal-731235, Email: sujit_kakali@rediffmail.com

(C) 2018 Saha, Goswami and Paul. This is an Open Access article distributed under the terms of the Creative Commons Attribution License (http://creativecommons.org/licenses/by/2.0), which permits unrestricted use, distribution, and reproduction in any medium, provided the original work is properly cited.
} 


\section{Introduction}

Migration is as old as the human civilisation, a silent and recursive social phenomenon inherent to the history of humanity. Migration is reported to have increased in the postliberalised economy causing large-scale mobility of workforce in developing nations. In addition, extreme poverty, ${ }^{1}$ stressed ecosystems ${ }^{2}$, climatic hazards, and sociopolitical shocks drive people out to distant places (Parkins, 2010). Since a large proportion of this out-migration involves male family members, leaving their women counterparts at the source, it is bound to affect the well-being of the women members of the family both positively and negatively. Available literature on migration is more inclined to explore the condition of migrants at the destination and the contribution of migrants (through remittance) to the welfare of their household. It largely overlooks the condition of people leftbehind at source, especially of the women, their lives, well-being and relationships with migrants (Toyota, Yeoh, \& Nguyen, 2007). Fortunately, a new trend of scholastic enquiry has delved into the exploration of this ignored area in migration research. The occurrence of male migration is also expected to transform traditional gender roles in rural societies and might influence the process of women empowerment directly and/or indirectly. Since a number of ongoing programmes on the empowerment of rural women are being implemented by the public and voluntary sector in developing nations, the examination of women's probable empowerment as an

\footnotetext{
1 The United Nations (1995) defines extreme Poverty as "a condition characterised by severe deprivation of basic human needs, including food, safe drinking water, sanitation facilities, health, shelter, education and information. It depends not only on income but also on access to services", which was later quantified as $\$ 1.25 /$ day (at 2005 prices) by the World Bank.

2 An ecosystem marked by poor productivity, profitability, stability and sustainability; most of the rain fed areas and parts of coastal saline zones of India embody stressed ecosystem. In the Sundarbans, prolonged inundation, high soil salinity in dry months and climatic extremes render the ecosystem extremely stressed.
}

outcome of recursive male migration instigates academic inquiry and justifies the need of this study.

When husbands migrate, wives have to perform additional household responsibilities hitherto primarily undertaken by their male counterparts, apart from performing traditional gender roles. The stereotypical gender roles in rural society, thus, tend to gradually break down and get diversified, leading to the expansion of women's involvement in different spheres of life (Radel, Schmook, \& McCandless, 2010). Expansion of opportunity is not confined to household works only but envisages participation in the works related to agriculture and allied sectors, which is increasingly being reported as 'feminisation of agriculture' ${ }^{3}$ (du Guerny, 1995). The expanded role of women also transcends household chores and includes community and institutional affairs. While some of the role expansions are advantageous to women, others may lead to the drudgery of women affecting their health and nutritional status undesirably (Singh et al., 2011). A mismatch of responsibility with the access to and/or ownership of resources and services often exacerbate the situation of women (Rao, 2006; Lastarria-Cornhiel, 2006).

In this context, a paradigm of research named 'migration left-behind nexus' emerged in recent years (Toyota et al., 2007), which focuses on the life experiences and well-being status of the women living at the origin during their husband's absence. Gendered studies on migration often explored the life of women migrants (Morokvasic, 2004) but employed less attention to non-migrant women who are affected by the migration of male members

\footnotetext{
3 The term connotes the increase in women's participation in agricultural sector, especially in the developing world (Deere, 2009). Boserup's (1970) seminal work brought the issue of gender vis-à-vis agriculture in mainstream literature. Later, women's participation in agriculture started to escalate during the economic liberalisation with increased mobility of male labour from rural to urban sector rending smallholderfarming systems largely driven by women (World Bank, FAO \& IFAD. 2009). We elaborate the issue in Section 3.4 of this article.
} 
from their family (Hugo, 2000). As a matter of fact, the existing literature under this paradigm is largely inclined towards transnational migration (Gartaula, Visser, \& Niehof, 2012; Sarkar \& Islam, 2014). Very few of them explicitly deal with circular and recursive nature of migration, which is a common feature in many developing nations due to the seasonal feature of farming. In fact, it is an accepted fact that internal and recursive labour migration has increased manifold in recent decades (Rosewarne, 2010). Moreover, attempt to understand the impact of male out-migration within the framework of women empowerment has also been largely absent (Sinha, Jha, \& Negi, 2012). Further, the male members' absence might affect the care and well-being of children and the elderly in the families. Thus, a literature gap exists not only on women left-behind but also, on the multiple pathways created by male out-migration and the intervening factors that define and shape the trajectory of these pathways in rural areas.

According to the UNDP Human Development Report, 2014 India is ranked 'medium' regarding human development ( $\mathrm{HDI}=0.586$ ). According to the same report, gender inequality (GEI) stands at 0.563, while the gender development index (GDI) stands at 0.828, which implies a practical urgency of women empowerment in national policy and practices. The explicit commitment to women's empowerment, a global phenomenon, in three of the eight Millennium Development Goals justifiably addresses this concern. Several initiatives for rural women have also been adopted by the Government of India in the last three decades to empower women. However, limited achievement has been accomplished in ensuring household and community level decision making, balanced work-force participation and many of the desirable outcomes of human well-being. Hence, there is a serious motivation to know how the spontaneous, perpetuate and wide-scale incidence of male outmigration affects the well-being of women left-behind in rural areas with special reference to their anticipated and unanticipated empowerment.
We undertake a systematic review of the recent global literature to examine the diverse pathways of recursive male outmigration in developing countries in the last two decades. We scrutinise how this phenomenon of recursive male out-migration in rural areas affects the well-being of 'left-behind' women and their family members with special reference to their empowerment and its associated factors.

\section{Review of Methodology}

Both migration and women's empowerment are loaded constructs with social, economic and political dimensions (Moghadam \& Senftova, 2005). This understanding is helpful to appreciate the anticipated causal relationships between different trajectories of male out-migration with special reference to women's empowerment. It is important that we conceptualise this relationship based on systematic scanning of available literature instead of intuitive reading and arguments. It is known that case study or single source of information on a given issue may generate rich insight, infer the relationship between variables or develop a theory on an issue. Nevertheless, it often requires information from a wider universe (Plummer et al., 2012). The literature survey is no exception to this since it is also laden with the biases of social surveys and validity of making conclusions based on a single or limited number of reviews is never beyond question (Petticrew\& Roberts, 2006). Thorne, Jensen, Kearney, Noblit, \&Sandelowski (2004) propose synthesis-based methodologies to address this limitation and recommend generation of new knowledge from in-depth analysis of existing research findings. They distinguish its data collection, treatment and detection of literature gap clearly from single reviews (Plummer et al., 2012). Although systematic reviews have widely been quantitative in nature, recently, systematic qualitative reviews are also being used as a handy methodology (Balaam et al., 2013).

A four-step approach for the systematic review and analysis of literature was undertaken for the present work (Plummer et al., 2012). First, 
the objectives of the review were set to study the effect of male out-migration on empowerment of women family members in terms of social, economic and political dimensions. Second, we established a search protocol including a selection of keywords, bibliographic databases, established criteria for selecting items from search engine returns etc. We used a combination of keywords involving "out-migration" or "male out-migration" and "women empowerment" or "women's empowerment" along with the related keywords that emerged in the course of searching databases. We used Scopus/Science Direct, Google Scholar and DOAJ as the bibliographic databases and considered the first 50 'hits' in the search engine for screening literature. We continued to search 'cited by' and 'related studies' (first 50 'hits') in Google Scholar. Third, we screened the results that fulfilled some criteria such as publication in the last 20 years, article published in English, article published in peer-reviewed journal, keyword match etc. Fourth, analysis of the literature was performed through the principle of qualitative analysis of literature that involved iterative coding ${ }^{4}$ of themes related to the study objectives (Corbin \& Strauss, 2008).

In this article, we start with the conceptualisation of migration in the light of historical and recent literature. Then, we discuss the consequences of male outmigration at the source and take up feminisation of agriculture as a special phenomenon within this. We, then, examine the issue of migrationinduced changes on the lives of women leftbehind within the framework of women's empowerment and examine the factors that influence this migration-led empowerment process. We extend the issue of migration-

\footnotetext{
${ }^{4}$ The inductive coding procedure that grounds on the data and repeated several times to unearth patterns, themes, and categories from it; in this study, the individual articles were coded following inductive process. That means codes were not imposed prior to the actual study of the articles (e.g. based on existing theories). The codes were also re-examined repeatedly to modify or recode them, thus, maintaining the objectivist application of the coding process.
}

induced impacts to the care of the left-behind child and the elderly. This is followed by a small description of methodological diversity employed in the migration-left-behind-nexus literature.

\section{Review Outcome}

\section{Understanding Migration}

\section{Prologue}

While writing this introductory section of the review outcome, we intentionally avoid citing the classical theories that explain migration, primarily because they were published well before the time limit set for this systematic review. However, we cite those that fall outside the specified time span (last two decades) if they have been commonly cited in the ongoing discussion to explain the phenomenon of migration. We refer the readers to the classical works of Ravenstein (1885), that relates physical distance of source and destination with the volume of migration along with several other propositions. ${ }^{5} \mathrm{We}$ also request our readers to read Lewis's (1954) work on economic development and labour supply in the context of developing nations, and Ranis and Fei's (1961) postulation of migration as a mechanism of equilibrium between wage in the agricultural and industrial sector. We do also refer to the seminal work embodied in Harris and Todero (1970) model that explains ruralurban migration based on wage differentials and many of its critiques (Gugler\& Flanagan, 1978; Fields, 1975; Kelly \& William, 1984). However, all these critiques operate within the Harris and Todero framework (HT Framework)

\footnotetext{
${ }^{5}$ In his historical paper published in the Journal of the Statistical Society of London, Ravenstein (1885) listed seven laws of migration - the majority of migrants go only a short distance; migration proceeds in stages; the process of dispersion is the inverse of that of absorption, and exhibits similar features; each main current of migration produces a compensating counter-current; migrants proceeding long distances generally go by preference to one of the great centres of commerce or industry; the natives of towns are less migratory than those of the rural parts of the country, and females are more migratory than males. Many of these propositions, later, formed the basis of migration research in the next decades.
} 
and suggest its modification instead of questioning its fundamental assumptions. A major shift came in the 1990s in the form of New Economics of Labour Migration (Massey et al., 1993). We are particularly eager to introduce the readers to this paradigm (along with livelihood models) because it heralded as a shift from individual to household/family (as a unit of analysis) while researching migration. This is important in our study since we are talking about the impact of male out-migration on women and family welfare, which does not fit well in the individualistic neo-classical models hinging mostly on wage differentials. However, we draw judicially from multiple streams of literature to establish a functional explanation of migration as they are used in the current literature.

\section{Conceptualisation of Migration}

Migration is a "process of moving, either across an international border or within a State. It is a population movement, encompassing any kind of movement of people, whatever its length, composition and causes; it includes migration of refugees, displaced persons, uprooted people, and economic migrants" (International Organisation for Migration, 2004:41) and operationally, a person is considered a migrant when he/she is "enumerated in census at a different place than his/her place of birth" (Census of India, 2011; p.2). Dominant theory suggests that both 'push' factors such as low wages or high unemployment at source (the HT framework), and 'pull' factors such as chronic and unavoidable need of workforces at destinations are 'causal' to the migration process (Stark \&Levhari, 1982). Classical literature suggests that all these forces are governed by wage differential (between rural and urban sectors or farming and industrial sectors), and all other factors remain subservient to it (Wang, Maruayama, \& Kikuchi, 2005). Another stream of literature suggests that two causes primarily drive migration of rural male to the urban or suburban area - the 'growth pull' and/or the 'crowding out' effects. Under the 'growth pull' effect, the destination holds better success and growth in terms of earnings (Islam, 1996). On the other hand, 'crowding out' takes place when there is saturation in labour supply from an inadequate local economic prospect (Deshingkar, 2004). However, it is understandable that both these explanations operate well within the framework of HT model and its assumptions.

When talking about the migration of labour force from rural areas, primarily three conjectures are employed to explain labour migration. First, in the 'dual economy model', labour movement is thought of as a voluntary and rational choice of the migrant in search of higher income (Mosse et al., 2002); second, according to the Marxian interpretation, labour mobility is a result of class exploitation of migrants by dominant classes in rural societies (de Haan \& Rogaly, 2002); and third, the 'neoMalthusian' explanation of migration employs pluralistic clarifications such as ecological stress, declining scope in the agricultural sector, debt cycle, demographic burden, exhaustion of natural resources, etc. (Deshingkar, 2008). From this outlook, Bernstein (2010) explains the scenario of the modern capitalist world, especially in the agrarian context, where production and reproduction are based on the fundamental social relation between capital and labour. In areas of the agrarian crisis caused by recurrent non-profitability of agriculture (due to the higher cost of production and vulnerability of open market), migration is not bounded by the 'choice' of villagers but is the single livelihood opportunity left for the large commercialised society. The New Economics of Labour Migration (NELM) that matured in the 1990s saw labour migration as a strategy that reduces household risk, increases income and at the same time overcomes constraints created by market imperfection (de Haan, 1999). Summarily, in spite of theoretical multiplicity, the causes of migration can be viewed against a 'rational choice' vs 'exclusion' continuum, although the points in between these two extremes are not necessarily exclusive mutually. In a dynamic rural society, these points keep on changing, and a social class cannot typically be associated with that point 
of the continuum. However, the incidence of migration is found widely among marginalised groups of people in rural areas due to rural distress and shifting of livelihoods from farm to non-farm sector. The process is continuously shaped by external forces such as economic globalisation $^{6}$ (that tends to source cheap labour from rural areas) and local culture where migration is a tradition for ages. Rowthorn (2010) examines the external forces of migration and suggests that migration of rural population is not only caused by poverty, land reforms, the division of land, lack of employment opportunities, and natural calamities. Rural migration might well be due to the unequal development of regions and policy level changes affecting poor people by enhanced risk in one hand, and creation of opportunity on the other. Apart from these, 'population displacement' is often found to be related to environment-induced migration and is another external cause of migration (Gemenne, 2015).

The custom of youth's emigration and their social status are interconnected in many societies, as it might reflect one's success in life (Kandel \& Massey, 2002). The culture of migration is well ingrained in many developing nations, and it is difficult to explain the same based on the logic of either labour economy or the cultural milieu (Heering, Van Der Erf, \& Van Wissen, 2004). A group of researchers have tried to explain the migration of a certain area by the migrant's social network (de Haas, 2010). Network theory and Migration Systems theory describe and explain the nature, magnitude, destinations and the driving forces of migration. However, it is often contended that these theories prove inefficient to explain the equilibrium in migration process (Massey et al., 1993) and cannot account for the external factors and the internal processes that lead to

\footnotetext{
${ }^{6}$ Economic globalisation can be defined as "increasing interdependence of world economies as a result of the growing scale of cross-border trade of commodities and services, flow of international capital and wide and rapid spread of technologies" (Shangquan, 2000:1). We argue that this form of globalisation creates wage difference, which in turn facilitates migration.
}

increasing migration through networks (Ye, Wang, Wu, He, \& Liu, 2013). We pay limited attention to network theories in this article, assuming that these might be of less use to the readers since these are theoretically not yet linked with the conditions of women leftbehind.

\section{Understanding the Nexus of Neoliberalism, Migration and Women's Empowerment}

The debate over migration and its conjectured relationship with women's empowerment is deep-rooted and can be placed within a string of theorisations. Although migration has a long history in many places of the developing world, neoliberalism has shaped its destiny greatly by creating newer employment hubs in cities and establishing a gradient of wage between rural and urban areas (Pieke\& Biao, 2009). India launched its new economic reforms in 1991 that embodied the tenets of neoliberalism ${ }^{7}$. Economic regulations by the government were relaxed to give way to the market processes and as a result (along with many other 'push' factors mentioned earlier in this article), a large number of men started to gravitate towards the employment hubs. This migration, need not to say, is largely gendered and will have gendered consequences.

It is often suggested that neoliberalism has impacted women negatively (Chowdhury, 1995; Bhattacharyya, 2009). In spite of the uneven impact of neoliberalism on the labour market, it is argued that there has been growing inequality under the neoliberal economy, and the inequality is gendered (Ganguly-Scrase, 2001). In this economic system, women are increasingly excluded from

\footnotetext{
${ }^{7}$ Although there are debates on whether globalisation and neoliberalism can be used synonymously, we use them as equivalent terms (if not interchangeable) simply because this distinction will not greatly change the central purpose of this article. Moreover, as GangulyScrase (2003: 545) suggests globalisation as an expansion of neoliberal market economy since "market liberalization and trade liberalization have been the cornerstones of the globalizing process in India". In fact, globalisation has been an amalgam of the socio-cultural and economic process that diffused the idea of neoliberalism in India.
} 
productive employment due to low skill set or replacement of their skills by modern technology, and end up largely in marginal occupations (Mathew, 1995). We can easily understand that the wage gradient set between rural and urban centres largely attracts the labour force and patriarchal culture facilitates the movement of male members retaining the women to take care of the family and its traditional livelihood vocations (such as farming). As we have already hinted, such engagement might also change the traditional gender role and empower women, but we must not forget that the debate is to be consciously coughed out in this disadvantaged context of male out-migration, where women are left to less-paid or unpaid jobs to sustain the family and the idea of an ideal agrarian society. However, before we debate that, we must theorise the concept of 'empowerment' in the context of the present article.

'Empowerment' has been described to embody a wide range of concepts and outcomes. This might be because the root word 'power' itself is disputed and understood differently by different people. The concept of 'power' is defined as 'power over' (some people have control or influence over others, e.g. men over women), 'internalised oppression' (a survival mechanism used by oppressed people, that over time becomes ingrained in their behaviour), and 'power to' which is generative in nature and wish to see a group achieve what it is capable of (Rowlands, 1995a). This 'power to' is the term which comes closer to 'empowerment' and is achieved by the enhanced ability of the human to resist and challenge the 'power over'. Conventionally, empowerment is the process of bringing people into the decision-making process (who were outside it) in political and economic spheres. In the generative interpretation, empowerment entails the awareness of own interest in relation to others and participation in decision-making that influence such relationships. Feminists go beyond the formal and institutional definitions of power and interpret 'power over' by understanding the 'internalised oppression' (Rowlands, 1995b).
Thus, 'empowerment' is not only opening up the opportunity for decision-making but to consciously move towards 'power to' and 'power from within' to occupy and shape the space for decision-making. Empowerment, here, assumes three dimensions - personal (developing the sense of self, overcoming internalised oppression), close relationship (ability to negotiate the relationship with others), and collective (collective actions). See, Bhattacharyya's (2009) application of Rowlands' concept of empowerment in Indian context for further elaboration.

The concept of 'empowerment' has additional and unique implications when applied to women. This is because women are not just another disadvantaged group, but also a category that cuts across every social group. Moreover, interfamilial and household relations hold the key to women's empowerment, and it requires the transformation of institutional structures that perpetuate patriarchy (Malhotra \& Schuler, 2005). There is a recurrent and overlapping reference to the idea of control over resources and own life when conceptualising women's empowerment. Kabeer's (2001:19) definition captures the spirit practically - "[t]he expansion in people's ability to make strategic life choices in a context where this ability was previously denied to them", which establishes the importance of the 'process' through which women progress towards an improved condition. Kabeer captures 'choice' by three components - 'resources' (the conditions under which choices are made), 'agency' (through which choices are made), and 'achievements' (outcomes of choices) and the majority of the related literature directly or indirectly aligns with Kabeer's view. While 'personal', 'close relationship' and 'collective' are differential forms of 'agency', the enabling environment in the form of 'resources' and outcomes of empowerment as 'achievements' make Kabeer's conceptualisation of women's empowerment more amenable to measurement. 
Having said these, we contend that the concepts of 'resource', 'agency' ('personal', 'close relationship' and 'collective') and 'achievement' are all important to understand the empowerment of women left-behind. Enabling factors such as education, parental connections (wealth and power) etc. of leftbehind women affect the construction of their agency and are expressed in terms of their enhanced mobility, decision-making power, participation in public spheres among many other dimensions of empowerment.

\section{Consequence of Male Out-migration at Source}

Like many other social phenomena, migration may result in both 'positive' and 'negative' impacts on human life. This may be precisely appreciated if one examines the impact of migration at the origin and destination separately. In fact, the dominant literature has largely studied the migrants at the destination, especially in the context of transnational migrations. However, we concentrate mostly on its impact at the source that aligns precisely with the scope of this article. Migration plays a vital role in improving livelihoods of the family left at the origin (de Brauw, Mueller, \& Woldehanna, 2013a) by bringing better opportunities and remittance, which reduces risks and provides insurance against social, economic or natural threats (Adams \& Page, 2005). This phenomenon may be considered as a livelihood strategy for many poor households in rural areas. This interpretation is well in line with the NELM and Livelihood paradigm of migration theories that see migration as an expression of human agency against the structural constraints at the source (rural areas). This also departs from the individualistic framework propounded by the HT model and many of its derivatives.

Male out-migration results in more responsible 'left-behind' women engaged in household management. Maharjan et al. (2012) maintain that examination of such migration-induced gender consequences is important for sustainable rural development. Because the journey from gender specified role to diversified gender role creates space for gradual 'empowerment' of rural women in terms of many dimensions. Also, they influence the welfare of the family members dependent on the women left-behind. We will come back to this issue later in this article. Now, this stream of literature is particularly important for at least two reasons - first, it sheds light on the intra-family gender consideration in relation to migration; second, it extends and links the event of migration to the issues of wider social transformation. This helps us depart from the dominant engagement with the remittance-led development of source areas and assists us to look into the socio-cultural processes involved in it.

Several empirical studies (Nguyen, Yeoh, \& Toyota, 2006; Singh et al., 2011) maintain that when the males migrate women are compelled to perform diversified roles in the household and society, hitherto dominated by men. These include - decision making and participation in activities such as purchasing and buying farm inputs and products, borrowing/lending of money, general household budgeting and education of the child(ren). When the amount of remittance is low or infrequent, women can neither meet household needs properly nor can they hire labour to outsource physical engagements. Such families 'left-behind' fall into social vulnerability (Sabates-Wheeler \& Waite, 2003), social insecurity (Mergo, 2016), malnutrition (Davis \& Brazil, 2016), serious diseases, weakening of social bonding such as extramarital relationship (Schulden et al., 2014) among many other undesirable consequences. Irregular and inadequate amount of remittance sent by the male migrants or its discontinuance in extreme instances may cause the increased incidence of poverty in rural areas of developing countries. This may be exacerbated by the abandonment of women by their husbands causing poverty, malnutrition of family members, and sexual exploitation. Moreover, the childcare and care of adult members of the family might suffer heavily (Mergo, 2016).

Supplementary attachment of women with productive work never provides them with 
theopportunity to negotiate with their existing roles defined by society, which results in drudgery, physical sufferings, and frustration. This often leads to several social problems in rural areas. On the other hand, the male migrants are exposed to new environments, have greater possibilities of facing sociopsychological problems of adjustments, and have a lack of social capital, making them incapacitated to enjoy several basic human rights (Bremen, 1996). Due to the absence of such social support system, the bargaining power of human labour suffers beyond reconciliation. This, as an immediate consequence, affects remittance and family welfare at the source.

Although there are competing and parallel streams of literature on the consequences of male out-migration, it is often considered a valuable strategy for families whose opportunity to sustain livelihoods at source is often far from certain (Baey \& Yeoh, 2015). In fact, some reports suggest encouraging impact of migration on household livelihoods, especially in the context of voluntary migration. At the household level, migration coupled with the steady flow of remittance is thought to improve childcare and their educational outcome. The quality and diversity of food are also expected to improve that is directly linked to the health and nutrition of the family members. Participation in the workforce and wider scope of social interaction enhances skill and knowledge set of women. This asks for pursuing migration studies through the lenses of both positive and negative outcomes. Moreover, since rural development increasingly engages itself with sustainable livelihoods of rural people, the dual outcomes of migration may be examined within the livelihood frameworks (DFID, 1999) for delineating the resultant trajectories of male out-migration in rural areas. This will capture the outcomes both in terms of assets and in terms of vulnerabilities of rural people and its linkage with the meso- and macro-level policy scenario. This is also important since this aligns the debate within the transforming paradigm of migration research - that is, from individualistic analysis of migration to the family- and livelihood-centric analyses.

Outside these premises of household welfare, another stream of literature concentrates on the trajectory of positive outcomes of male outmigration mediated by steady remittance. Where do such remittances go? Are they invested in household asset creation or invested in productive activities such as farming? Literature suggests that although in most instances assets are indeed created at the household level, they are rarely invested back in the productive activities such as farming (Jokisch, 2002). It has however remained inconclusive how far these investments create an impact on enterprise productivity, local economy, and financial institutions. We come back to a few of these issues in the next section on 'feminisation of agriculture'.

\section{Feminisation of Agriculture}

Women's participation in agriculture is a historical fact, although the nature and extent of their participation have varied across time and space. However, due to improved data collection and women's deeper involvement in agriculture, women's participation in agriculture has become more visible in the last few decades (Lastarria-Cornhiel, 2006; Lokshin \& Glinskaya, 2009). While the share of the labour force in the agricultural sector declined over the 1990s, women's share in the agricultural labour force increased in developing countries (FAO, 1999:12-13, cited in Lastarria-Cornhiel, 2006). This trend has been called the feminisation of agriculture.

In a patriarchal society, women hold a subordinate position with respect to gender relations and power structure. Agriculture is no exception to this. In spite of playing significant and diverse roles in agriculture - as farmers, co-farmers, family labours, wage labours, women experience gender difference, women's contribution gets scarcely recognised as male farmers hold the image of a 'farmer' and control all farming related activities (Singh, 2014; Singh, 2015). When men move outside the community, it directly gives some power in the hand of women through expansion of their 
participation in the household as well as community decision-making process, and most importantly in agriculture, the mainstay of the household's economy. Women take up the major responsibilities of food production together with other household activities (the 'feminisation of agriculture)' (du Guerny, 1995; de Brauw et al., 2008).Evidence shows that women participate in most of the activities associated with agricultural production, household food production, food processing, storage and transport from farm to village, and water and fuel-wood collection for households (Patel, Patel, Desai, Patel, \& Patel, 2016). Migration of men results in an increased dependency of agriculture on women's labour participation, decision making and food production. Some authors posit that women dependent farm can hold the quality and quantity of production in the absence of male (Meng, 2014), others fear declining agricultural productivity due to increasing feminisation of agriculture (Lastarria-Cornhiel, 2006) in the absence of external support. In fact, feminisation of agriculture, in the absence of family, external or state support, has no necessary relationship with improved productivity/profitability, and women's social or economic empowerment; it might lead to 'feminisation of poverty' (Pattnaik, Lahiri-Dutt, Lockie, \& Pritchard, 2017). Unfortunately, women see-off several opportunities of skill development for handling their family farming, which is rarely recognised by the extension agencies. Therefore, women experience little access to extension services and little or no ownership to land rights, thus, accepting a burdensome life without enough recognised incentives to carry on agriculture in their husbands' farm (Kelkar, 2007).

Another stream of literature on political economy of migration argues that extended participation of women in agriculture and food supply is driven by the logic of lowest wage of women's labour force in the neoliberaleconomy ${ }^{8}$ (Lastarria-Cornhiel, 2006;

\footnotetext{
${ }^{8}$ Refers to the fiscal stabilisation policy adopted by many developing countries to achieve favourable balance of
}

Allen \&Sachs, 2007). Ironically, the same reason holds true for the increased male participation in off-farm wage-earning job sustained by male out-migration (Lastarria-Cornhiel, 2006). de Brauw, Huang, Zhang, \& Rozelle (2013b) classified agricultural feminisation in China into 'labour feminisation' and 'managerial feminisation'. 'Managerial feminisation' happens due to the male migration when women manage family farming by taking crucial decisions and enjoy access to farm income, whereas in 'labour feminisation' women's labour is invested in the crop production (de Brauw et al., 2013b). Gartaula, Niehof, \&Visser (2010) distinguish these two forms of feminisation with the logic of power position and managerial practice of left-behind women respectively. These two concepts may well apply to women headed de-facto household, perhaps, more in the context of women staying in patrilineal households with in-laws. Nevertheless, silently and steadily management of the farming system is being transformed into the hands of women through altered gender participation in agriculture (Radel, Schmook, McEvoy, Mendez, \&Petrzelka, 2012), which needs deeper understanding.

From the policy perspective, it is very important to understand the impact of such 'feminisation' on agricultural production and productivity. Studies about agricultural productivity in women managed farms do not have a consensus. While a majority of the studies suggests a decline in farm productivity, others are more cautious in making such conclusions in the absence of enough extension support for women-managed farms (de Brauw et al., 2013b). Other literature suggests policy initiatives to sustain farm productivity in women managed farms by introducing gendersensitive technology and human resource

payments, control inflation rates, and increase exports; structural adjustment policy was used to achieve import liberalisation, privatisation of government sector resources and services, and liberalising the labour, land, and capital markets (Lastarria-Cornhiel, 2006). Exportoriented agricultural farms hired temporary, casual and low-wage female labour force, thus, increasing women's participation in agriculture. 
development (Reddy, Rani, \& Reddy, 2015) or taking care of household-level food security (Tamang, Paudel, \& Shrestha, 2014). However, the third stream of literature reflects on the rights-based approaches and advocates gender mainstreaming in agricultural research and extension systems to address multiple issues associated with feminisation of farming (Rao, 2006).

\section{Out-Migration vis-à-vis Status and Empowerment of Left-behind Women}

We have known that migration literature is predominated either by the conditions of the migrants in the destinations, or their economic contributions to their households and communities, without investing much attention to the socio-cultural context of migration (Sharma, 2008). The literature also overlooks the issues with the people left-behind, their lives, experiences, well-being and relationships of migration with these beings, especially that of women (Nguyen et al., 2006; Yeoh, Huang, \& Lam, 2005). Recently, scholars have started exploring the lives of the people left-behind which may be put under the tradition of 'migration-left-behind nexus' (Jones \&Kittisuksathit, 2003; Rigg, 2007; Toyota et al., 2007). The women left-behind are often invisible, and we have little understanding of their role, experience, well-being and interconnectedness with the practice of migration (Nguyen et al., 2006). Understanding of their 'statuses and 'empowerment' in a theoretically consistent manner has been a challenge to the researchers.

Authors have often used the concept of 'status' and 'empowerment' to study the impact of male migration on women left-behind. Where 'status' refers to one's stand and prestige in society (de Brauw, Li, Liu, Rozelle, \& Zhang, 2008), 'empowerment' connotes the ability of women to make strategic life choices which they were previously denied of. As already discussed earlier, empowerment is understood in terms of 'resources' (the enablers for the process of making such choice), 'agency' (the ability to make strategic choices) and 'achievements' (the expression of empowerment) and expressed in terms of decision-making power, personal freedom, mobility, access to and control over resources, and freedom from violence (Kabeer, 1999) among many other economic, socio-cultural, familial/interpersonal, legal, political and psychological indicators (Malhotra \& Schuler, 2005). The migration of men has a clear influence on the status of women left-behind in villages, which can be positive or negative when measured by one or other of these indicators. While a stream of literature argues for breaking of skewed gender roles through women's enhanced responsibilities in their family and community, hitherto taken care of by their male counterparts (Desai \&Banerji, 2008; Meng, 2014), others reports increased drudgery of women without any substantial incentives and right to resources (Singh et al., 2011; Meng, 2014). Male out-migration creates space for women to renegotiate gender relationships, increase decision-making power and access to and control over resources. These indirectly emancipate rural women by reconstructing the dominant gender roles and power structure in the society (Sabur\& Mahmud, 2009). This is closely related to the achievement of strong 'agency' at both 'personal' and 'collective' levels. This invisible, yet consistent social process strengthens several important facets of women's lives such as their mobility, participation in the labour force, intra-household decision making, social recognition (Desai \& Banerji, 2008), de-facto access to resources, enjoyment of social networks and few others yet to be established in the literature. Empirical evidence from several countries such as - Armenia, Guatemala (Menjívar \& Agadjanian, 2007), Morocco (Sadiqi \&Ennaji, 2004), and Bangladesh (Hadi, 2001) reports greater decision-making, management of duties, and autonomy of women after the migration of their male counterparts. These attainments are often retained even after returns of the male migrants. Apart from these, due to the persistent change in gender role, society's evaluation of the women's status also change over time. Such changes might reduce the 
incidence of several social evils such as dowry ${ }^{9}$ (Hadi, 2001), gender discrimination (Mukharjee, 2013), wife battering (Donta, Nair, Begum, \&Prakasam, 2016), etc. Moreover, the demonstration effect of males coming back from cities also triggers behavioural modification through the introduction of new ideas by the migrants. This is further diffused among the members of the community. Taken all these together, we find a cyclical reinforcement of 'enabling environment', 'personal' and 'collective' 'agency' and 'achievements' of women that reshapes the confrontation of 'power to' and 'power within' with 'power over' in the society.

However, there are several studies that report negative and/or mixed outcome on women left-behind (Maharjan et al., 2012; Agadjanian \& Sevoyan, 2014). The autonomy of women may be challenged by 'moral propriety' (Chant, 1998) and social 'policing' (Gledhill, 1995). It may also render increased work burden and drudgery to the women, especially due to the increased feminisation of agriculture in developing nations. The increased burden without appropriate capacity building and rights may usurp the anticipated gain through expanded gender role. The changing gender role is also challenged by threats in public space, fear of sexual harassment and imposition of cultural control when the presumed empowerment shows the potential threat to patriarchal control. Further, the absence of husbands is always related to the vulnerability and insecurity of left-behind women, which is difficult to negotiate in a patriarchal society. Also, when husbands come back from distant places, they often cause enhanced risk of left-behind wives to sexually transmitted diseases including HIV/AIDS (Agadjanian \& Sevoyan, 2014).

\footnotetext{
${ }^{9}$ The transfer of parental property, gifts or money to the bridal family at the marriage of a daughter (Goody, 1976) and often leads to violence against the bride; it has a long history in Europe, South Asia and Africa and its magnitude is reported to have increased significantly in India (Banerjee, 2014).
}

This hypothesised migration induced empowerment of women are reported to be affected by factors such as attribute of women (age, education, marital duration, status of father's house), nature and amount of remittance, family structure (nuclear, joint extended), local culture (Sinha et al., 2012) and their complex interplay. Personal attributes of the women play a significant role in shaping their agency and exercising actions leading to empowerment. Increase in the age of women is often found to enhance their status and agency in the family and community (Boateng et al., 2014). Higher educational attainment of women also facilitates empowerment by inducing higher perceived status in the eyes of the community. Longer marital duration is related to the higher autonomy of women since they take care of the children and other family members and they also need relatively lesser 'moral policing'. Higher status of father's house is also reported to reduce the vulnerability of women and indirectly allows greater autonomy to the women.

\section{Factors Associated with the Remittance- Mediated Empowerment}

The literature on male out-migration vis-a-vis the 'left-behind' women have so far suffered from endogeneity of migration (Antman, 2012) and failed to clearly address the factors that shape such outcomes (Ye et al., 2013). Southiseng and Walsh (2011) evidenced a link between remittance and roles of women by recognising four different areas of spending remittance such as - family security and wellbeing, fungible events, economic activities and community development. Study on remittance within the tradition of migration research has also addressed gender dimension related to the access to and/or control over remittances. This is important since the left-behind women's and their families' well-being greatly depends on how and how much remittance is sent to them and how they are utilised. There is an association between women's access to remittance and their ability to make household and community level decisions in the absence of their husbands. Also, the educational status 
of women is conjectured to be related to the management of remittance, thus, influencing the empowerment and well-being of the leftbehind wives (Sabur\& Mahmud, 2009). Apart from these, the family structure influences the achievement of liberty and independent decision making within the household. Women left-behind in a nuclear family enjoy more freedom and essence of agency than the women living in an extended family setting (commonly known as the joint family) (Yabiku, Agadjanian, \&Sevoyan, 2010). In joint extended families, the decision making power lies with the male members, and they also control the way remittance is used. Thus, in spite of a steady flow of remittances, empowerment might not be achieved in joint extended families. This is important since the access to and control over remittance can improve women's well-being in agrarian society by lessening their workload through hired farm labour (using the remittance).

Left-behind women are to interact with various organisations in the absence of their husbands for accessing social assistance and sustaining livelihoods (Yabiku et al., 2010). Male migration also accelerates women's mobility while working as agricultural labour and cultivator, when visiting children's schools, doctors, the local markets, and when purchasing groceries (Datta \& Mishra, 2011). On the other hand, lack of access to remittance in joint families or abandonment of left-behind wives by husbands may lead to social exclusion and extreme deprivation of the women (Roy \&Nangia, 2005; Ahlin\& Dahlberg, 2010). These women often have to spend their lives in their father's place and get engaged in religious activities, child rearing, household works, etc. Else, they are considered to be a burden to family (Sabur\& Mahmud, 2009). This affects the agency of the left-behind women and leaves space for unfortunate exploitation in the labour market. Their health and nutrition are severely compromised, and they suddenly find themselves in extreme poverty. Socio-sexual behaviour changes as a response to such acute sense of insecurity and vulnerability. Such undesirable outcomes affect the care of children and old-aged family members. This might result in poor education or schooldropout among children and much senilityrelated health and psychological disorder among the aged people. Unfortunately, the extent of out-migration and its impact on women's empowerment have received insufficient policy attention (International Fund for Agricultural Development, 2005) and inconclusive empirical evidence.

\section{Care of Left-behind Child and Elderly}

A recent stream of literature extends the 'migration left-behind nexus' to the issue of the welfare of children and elderly persons (Chang, Dong, \&MacPhail, 2011). The departure of the male has been evidenced as both beneficial and detrimental for different ages of children and parents at the origin. Financial outcomes of male migration in the form of remittance, large and balanced or marginal and sporadic, influence the health, nutrition (Zhou et al., 2015) and educational achievement (Antman, 2013) of left-behind children irrespective of their age and sex. In many places of Eastern India, male out-migration is a culturally accepted livelihood strategy and their educational outcome may either be positive or negative, depending on the flow of remittance and the socio-economic marginalisation of the family (Roy, Singh, \& Roy, 2015). However, it will not be out of the context to observe that socio-economic marginalisation (e.g. among the tribal population) almost always negatively influences the welfare of children, be it at the source or destination (Das \& Das, 2014). Reduction in remittance flow or no remittance pertains to social exclusion, which would probably link to an increased rate of child labour in a region (Alcaraz, Chiquiar, \& Salcedo, 2012). Again, remittance from migrated sons is reported to have improved the material wellbeing of their elderly parents left-behind in rural areas. But, adverse situations demand social support from a distanced child, which is negotiated by telephonic conversation and their visit at long intervals (Knodel \& Saengtienchai, 2007). The study of de Haas (2010) depicts the delaying of male migration 
unless a suitable male relative is available to take care of his left-behind family - wife, children and parents. In fact, the culture of migration might encourage gender reshaping within the household context, which is mediated by traditional rural customs. It has been expressed in the form of performance of fundamental role played by women to provide care, assistance and kin-keeping to ensure the social security of the family (Liu, 2014).
However, the parting from husband and shouldering of unrealised accountability to the extended in-laws would be the cause of exhaustion and discomfort rather than empowerment of wives (McEvoy, 2008).

To assist the readers, we summarise the components of Figure 1 and indicate its nature of the impact on the left-behind households along with supporting literature (Table 1).

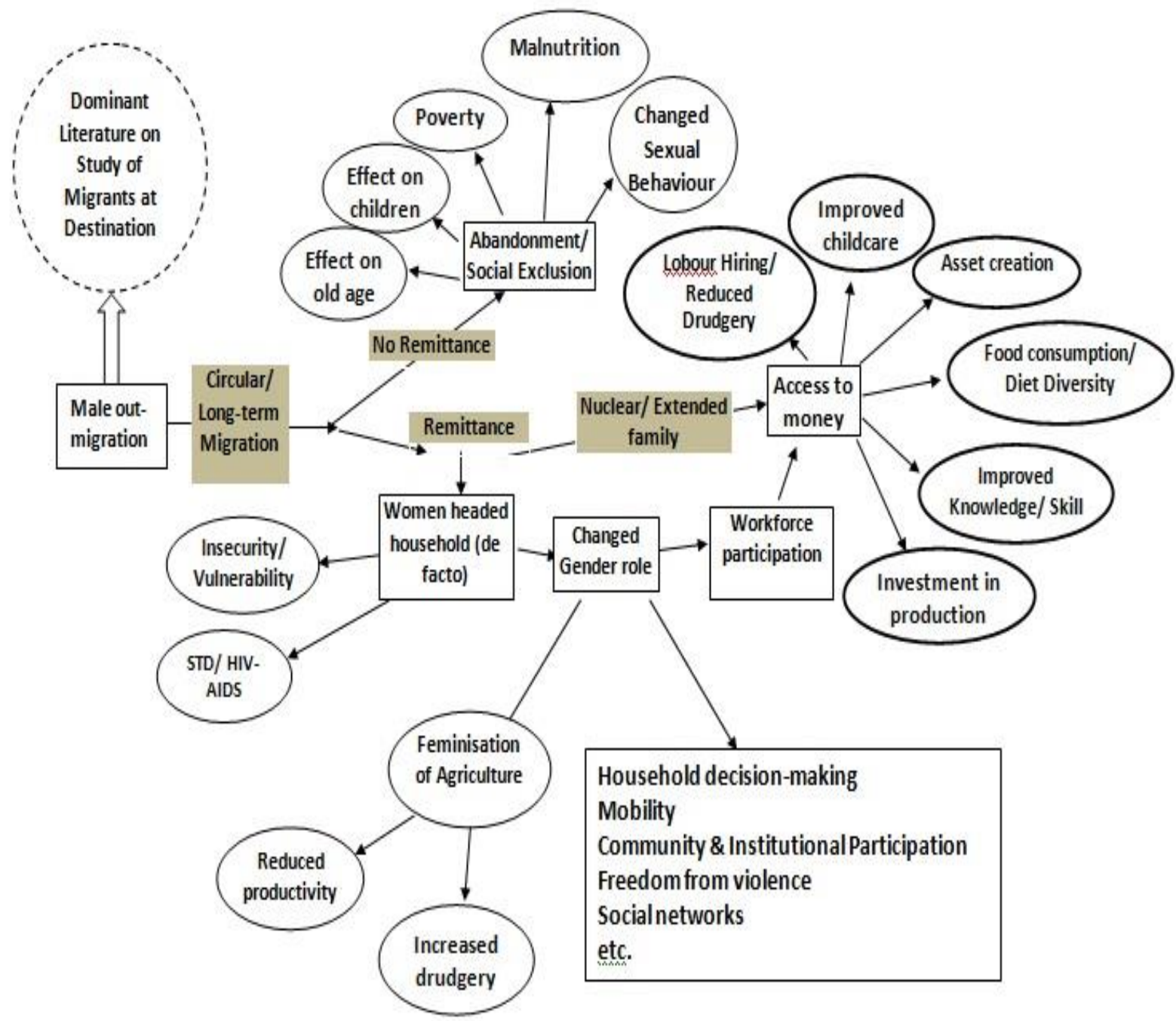

Figure 1: Literature Map Showing Existing Status of Literature on Recursive Migration vis-à-vis Status of Women 


\section{Table 1: A Summary of Women Left-behind Nexus Literature}

\begin{tabular}{lll}
$\begin{array}{l}\text { Manifestation of effect on } \\
\text { 'women left-behind.' }\end{array}$ & $\begin{array}{l}\text { Positive or } \\
\text { Negative }\end{array}$ & Source \\
\hline Feminisation of household & Both & Chant (1998), Hadi (2001) \\
Change in gender roles at & Both & Desai \& Banerji (2008), Meng (2014)
\end{tabular}

household/community levels

Participation in labour force

Positive Durand \& Massey (2004), Lokshin\&Glinskaya (2009)

Feminisation of agriculture and Both de Brauw et al. (2008), Radel et al. (2010), allied activities Radel et al. (2012), Meng (2014), Tamang, et al. (2014)

$\begin{array}{lll}\text { Reduced drudgery/workload } & \text { Positive } & \text { Maharjan et al. (2012) } \\ \text { Enhanced drudgery } & \text { Negative } & \begin{array}{l}\text { Meng (2014), Singh et al. (2011), Sadiqi } \\ \text { \&Ennaji (2004) }\end{array} \\ \text { Steady remittance } & \text { Positive } & \begin{array}{l}\text { Posel (2001), Kothari (2003) } \\ \text { Rights to assets/resources }\end{array} \\ \text { Both } & \text { Kelkar (2007) }\end{array}$

Increased household decision Positive Hadi (2001), Desai \& Banerji (2008), Yabiku et making al. (2010), Elbadawy \& Roushdy (2010), Datta\& Mishra (2011)

\begin{tabular}{|c|c|c|}
\hline Community participation & Positive & Maharjan et al. (2012) \\
\hline Participation in institutions & Positive & Chathukulam\& John (2000) \\
\hline Insecurity & Negative & Menjivar \& Agadjanian (2007) \\
\hline Nutrition/health & Both & Roy \&Nangia (2005) \\
\hline Reproductive behaviour & Both & $\begin{array}{l}\text { Agadjanian et al.(2011), } \\
\text { Agadjanian \& Sevoyan (2014) }\end{array}$ \\
\hline Childcare & Both & Kausaret al. (2014) \\
\hline Children's education & Both & Antman (2013) \\
\hline $\begin{array}{l}\text { Sexually transmitted } \\
\text { diseases/HIV-AIDS }\end{array}$ & Negative & Agadjanian \& Sevoyan (2014) \\
\hline Abandonment/exclusion & Negative & Sadiqi \& Ennaji (2004) \\
\hline Social exclusion & Negative & Roy \& Nangia (2005), Kothari (2003) \\
\hline \multicolumn{2}{|c|}{$\begin{array}{l}\text { The Methodological Diversity } \\
\text { Apart from studying the theoretical contour of } \\
\text { migration-led empowerment of women-left- } \\
\text { behind, we take up an independent analysis of } \\
\text { methodologies employed in the relevant } \\
\text { studies. We identified } 22 \text { empirical works } \\
\text { (following the criteria mentioned in review } \\
\text { methodology) for the analysis and found that }\end{array}$} & $\begin{array}{l}\text { most of the works were conducted using } \\
\text { primary data (Figure 2). Majority of these works } \\
\text { followed mixed method approach, followed by } \\
\text { purely quantitative and purely qualitative } \\
\text { approaches. Given the emerging nature of the } \\
\text { literature, one could expect more qualitative } \\
\text { engagement with data in the coming years. This } \\
\text { will be particularly relevant for studies that } \\
\text { record the life experiences of women. We }\end{array}$ \\
\hline
\end{tabular}


assume that the researchers so far have mostly been trying to describe the situation of leftbehind families based on their knowledge of existing theories and grounding theories based on field data is yet to become common. A discussion of this skewed methodological engagement might claim space in a separate article.
Male Out-migration and Women Empowerment (22)



Figure 2: Methodological Engagement of Representative Literature on Migration-led Empowerment of Women

\section{Conclusion}

Socio-economic and demographic profile of rural areas in developing countries is changing radically in the face of the liberalised economy. In this article, we have tried to take account of existing literature to show how recursive male out-migration from rural areas is causally linked to the status and/or well-being of left-behind women. Since social changes are overarching and omnipresent, the impact of male outmigration on women left-behind cannot be reflected upon without an engagement into the larger socio-cultural rubric of an area. There is clear indication of both positive and negative changes in the lives of these women through increased work participation, particularly in farming, and a continuous negotiation with the traditional gender roles. This process is also linked to the economics of remittance and its use, the pattern of remittance being the most important determinant of the well-being of the left-behind. This is followed by the consideration of socio-cultural context that guides the balance of positive and negative outcomes for the left-behind families. A comparative analysis of interactions and tradeoffs between these outcomes is also largely missing in the existing literature.

The question of how the transformation of women is seen by themselves and the society at large is another issue, which is inadequately addressed in the literature. Often women may not find this overburdened state as 'emancipation', and this could be troublesome for many of them, given the fact that they have not made an informed choice against the existing social norms. However, in the long term, the society might change its normative position and let the patriarchal burdens lose for its sustenance in the wake of increasing male 
outmigration. And when migration continues to the next generation of male, it initiates a longterm social change where society understands (not without the conscious 'agency' of women themselves) the value of women's labour both in the presence and absence of male members in a family. Thus, the debate on the 'impact of male outmigration on the status of women' itself is not theoretically sufficient. It is never free from the general economic and sociocultural processes and the role of government in pushing the cause of women's empowerment through various programmes. This asks for a deeper analysis of migration-led women's empowerment. The present analysis of literature describes the issue only partially and strongly looks forward to empirical studies that take up both migration-led transformations in women's agency along with many related ongoing economic and sociocultural processes for a better understanding of this stream of growing knowledge.

\section{References}

Adams Jr, R. H., \& Page, J. (2005). Do international migration and remittances reduce poverty in developing countries? World Development, 33(10), 1645-1669.

Agadjanian, V., \& Sevoyan, A. (2014). Embedding or uprooting? The effects of international labour migration on rural households in Armenia. International Migration, 52(5), 29-46.

Agadjanian, V., Yabiku, S. T., \& Cau, B. (2011).Men's migration and women's fertility in rural Mozambique. Demography, 48(3), 10291048.

Ahlin, S., \& Dahlberg, A. (2010). Migration, remittances and the women left behind: $A$ study on how women in Mali are affected by migration and remittances from their migrated husbands. Sweden: Linnaeus University.

Alcaraz, C., Chiquiar, D., \& Salcedo, A. (2012).Remittances, schooling, and child labor in Mexico. Journal of Development Economics, 97(1), 156-165.

Allen, P., \& Sachs, C. (2007). Women and food chains: The gendered politics of food. In Williams-Forson, P. \&Counihan, C. (Eds.), Taking food global: Redefining foodways in a changing world (pp. 23-40). New York: Routledge.

Antman, F. M. (2012). Gender, educational attainment, and the impact of parental migration on children left behind. Journal of Population Economics, 25(4), 1187-1214.

Antman, F. M. (2013). The impact of migration on family left behind. In A.F. Constant \& K.F. Zimmerman (Eds).International Handbook on the Economics of Migration, (pp. 293308). Cheltenham: Edward Elgar.

Baey, G., \& Yeoh, S.A.B. (2015). Migration and precarious work: Negotiating debt, employment, and livelihood strategies amongst Bangladeshi migrant men working in Singapore's construction industry, Migration out of Poverty Research Programme Consortium, Working Paper 26, Brighton: University of Sussex, Retrieved from: http://www.solutionexchange-un-gengym.net/wpcontent/uploads/2015/11/Migration-andPrecarious-Work.pdf.

Balaam, M. C., Akerjordet, K., Lyberg, A., Kaiser. B., Schoening, E., Fredriksen, A., Ensel, A., Gouni, O., \& Severinsson, E. (2013). A qualitative review of migrant women's perceptions of their needs and experiences related to pregnancy and childbirth, Journal of Advanced Nursing, 69(9), 1919-1930.

Banerjee, P. R. (2014). Dowry in 21st-century India: the socio-cultural face of exploitation. Trauma, Violence \& Abuse, 15(1), 34-40.

Bernstein, H. (2010). Class dynamics of agrarian change (Vol. 1). Canada: Kumarian Press.

Bhattacharyya, R. (2009). Examining the changing status and role of middle class Assamese women: lessons from the lives of university students. Unpublished PhD Thesis, University of Newcastle, United Kingdom. 
Retrieved from:

https://theses.ncl.ac.uk/dspace/handle/104 $43 / 303$

Boateng, G. O., Kuuire, V. Z., Ung, M., Amoyaw, J. A., Armah, F. A., \&Luginaah, I. (2014). Women's empowerment in the context of millennium development goal 3: A case study of married women in Ghana. Social Indicators Research, 115(1), 137-158.

Boserup, E. (1970.) Woman's Role in Economic Development. Male and female farming systems. London: Earthscan.

Bremen, J. (1996). Footloose labour working in India's informal economy. London: Cambridge University Press.

Census of India. (2011). Data Highlights: Migration tables (D1, D1 (Appendix), D2 and D3 Tables). Retrieved from: http://censusindia.gov.in/Data_Products/Da ta_Highlights/Data_Highlights_link/data_hig hlights_D1D2D3.pdf

Chang, H., Dong, X. Y., \&MacPhail, F. (2011).Labor migration and time use patterns of the left-behind children and elderly in rural China. World Development, 39(12), 2199-2210.

Chant, S. (1998). Households, gender and ruralurban migration: reflections on linkages and considerations for policy. Environment and urbanization, 10(1), 5-22.

Chathukulam, J., \& John, M. S. (2000). Empowerment of women panchayat members: learning from Kerala (India). Asian Journal of Women's Studies, 6(4), 66-101.

Chowdhury, A. (1995). Employed Mothers and their Families in India. Early Child Development and Care, 113 (1), 1995, 65-75.

Corbin, J., \& Strauss, A. (2008). Basics of qualitative research: Techniques and procedures for developing grounded theory ( $3^{\text {rd }}$ ed.). London: Sage.

Das, S., \& Das, M. (2014). Income, Migration and Social Adjustment of Tribal People in Tripura- A Case Study of 'Tripuri' Tribe. Space And Culture, India, 2(1), 5-13.
Datta, A. \& Mishra, S. K. (2011). Glimpses of women's lives in rural Bihar: Impact of male migration. The Indian Journal of Labour Economics, 54(3), 457-477.

Davis, J. \& Brazil, N. (2016). Migration, remittances and nutrition outcomes of leftbehind children: A national-level quantitative assessment of Guatemala. PloS One, 11(3), 1-17.

de Haas, H. (2010). Migration and development: a theoretical perspective. International Migration Review, 44(1), 227264.

de Brauw, A., Mueller, V., \&Woldehanna,T. (2013a). Does internal migration improve overall well-being in Ethiopia? Ethiopia Strategy Support Programme, ESSP Working Paper 55, Retrieved from: http://citeseerx.ist.psu.edu/viewdoc/downl oad?doi=10.1.1.352.6060\&rep=rep1\&type= pdf

de Brauw, A., Huang, J., Zhang, L., \&Rozelle, S. (2013b). The feminisation of agriculture with Chinese characteristics. The Journal of Development Studies, 49(5), 689-704.

de Brauw, A., Li, Q., Liu, C., Rozelle, S., \& Zhang, L. (2008). Feminization of agriculture in China? Myths surrounding women's participation in farming. The China Quarterly, 194, 327-348.

Deere, C. D. (2009). The Feminization of Agriculture?The Impact of Economic Restructuring in Rural Latin America. UNRISD Occasional Paper, No. 1. Retrieved from: https://www.econstor.eu/bitstream/10419/ 148788/1/862541824.pdf

De Haan, A. (1999). Livelihoods and poverty: The role of migration-a critical review of the migration literature. The journal of development studies, 36(2), 1-47.

De Haan, A., \& Rogaly, B. (2002). Introduction: Migrant workers and their role in rural change. Journal of Development Studies, 38(5), 1-14.

Desai, S., \& Banerji, M. (2008). Negotiated identities: male migration and left-behind 
wives in India. Journal of Population Research, 25(3), 337-355.

Deshingkar, P. (2004). Understanding the implications of migration for pro-poor agricultural growth. Paper prepared for the DAC POVNET Agriculture Task Group Meeting, Helsinki, 17-18 June, 2004, Retrieved from: http://www.oecd.org/dac/povertyreduction /36562999.pdf

Deshingkar, P. (2008). Circular internal migration and development in India. In J. de Wind and J. Holdaway (eds.), Migration and development within and across broader: Research and policy perspectives on internal and international migration (pp. 161-188). Geneva and New York: International Organization for Migration (IOM) and Social Science Research Council (SSRC).

DFID.(1999). Sustainable livelihoods guidance sheet. United Kingdom: Department of International Development.

Donta, B., Nair, S., Begum, S., \&Prakasam, C. P. (2016). Association of domestic violence from husband and women empowerment in slum community, Mumbai. Journal of interpersonal violence, 31(12), 2227-2239.

duGuerny, J.(1995). Gender migration, farming systems and land tenure, (Module 4, SWWP). Rome: FAO.

Durand, J., \&Massey, D. S. (2004). Crossing the border: Research from the Mexican migration project. New York: Russell Sage Foundation.

Elbadawy, A., \&Roushdy, R. (2010). Impact of international male migration on women status: The case of Egypt. Paper presented to International Conference on Women and Youth in Arab Development, Cairo, Egypt, March 22-24, 2010.

Food and Agricultural Organization. (1999). Las estadisticasrelacionadas con el genero. Roma: FAO.

Fields, G. S. (1975). Rural-urban migration, urban unemployment and underemployment, and job-search activity in
LDCs. Journal of development economics, 2(2), 165-187.

Ganguly-Scrase, R., (2001). Women and Economic Development: a case study of lower middle classes in India. The International Scope Review, 3(1), 1-20.

Ganguly-Scrase, R. (2003). Paradoxes of globalization, liberalization, and gender equality: The worldviews of the lower middle class in West Bengal, India. Gender \& Society, 17(4), 544-566.

Gartaula, H. N., Niehof, A., \& Visser, L. (2010). Feminisation of agriculture as an effect of male out-migration: Unexpected outcomes from Jhapa District, Eastern Nepal. International Journal of Interdisciplinary Social Sciences, 5(2), 567575.

Gartaula, H. N., Visser, L., \& Niehof, A. (2012). Socio-cultural dispositions and wellbeing of the women left behind: A case of migrant households in Nepal. Social Indicators Research, 108(3), 401-420.

Gemenne, F. (2015). One good reason to speak of 'climate refugees'. Forced Migration Review, 49, 70-71.

Gledhill, J. (1995). Neoliberalism, transnationalization and rural poverty: a case study of Michoacan, Mexico. Boulder: Westview Press.

Goody, J. (1976). Production and reproduction: a comparative study of the domestic domain (No. 17). Cambridge: Cambridge University Press.

Gugler, J., \& Flanagan, W. (1978). Urbanization and social change in West Africa. Cambridge: Cambridge University Press.

Hadi, A. (2001). International migration and the change of women's position among the leftbehind in rural Bangladesh. Population, Space and Place, 7(1), 53-61.

Harris, J. R., \& Todaro, M. P. (1970). Migration, unemployment and development: a twosector analysis. The American economic review, 60(1), 126-142. 
Heering, L., Van Der Erf, R., \& Van Wissen, L. (2004). The role of family networks and migration culture in the continuation of Moroccan emigration: A gender perspective. Journal of Ethnic and Migration Studies, 30(2), 323-337.

Hugo, G.J. (2000). International migration and labour markets in Asia: Australia country paper, Paper prepared for the Workshop on International Migration and Labour Markets in Asia organised by the Japan Institute of Labour (JIL) supported by the Government of Japan, Organisation for Economic Cooperation and Development (OECD) and the International Labour Office (ILO), Tokyo:Japan Institute of Labour, January 2628, 2000.

Human Development Report (2014). Sustaining human progress: Reducing vulnerabilities and building resilience. New York: UNDP.

IFAD. (2005). Enabling the rural poor to overcome poverty. Rome: International Fund for Agricultural Development.

IOM (2004).International glossary on migration. Geneva: International Organization for Migration.

Islam, N. (1996). Dhaka: from city to megacity: perspectives on people, places, planning, and development issues (No. 1). Urban Studies Programme, Department of Geography, University of Dhaka.

Jokisch, B. D. (2002). Migration and agricultural change: The case of smallholder agriculture in highland Ecuador. Human Ecology, 30(4), 523-550.

Jones, H., \&Kittisuksathit, S. (2003). International labour migration and quality of life: Findings from rural Thailand. Population, Space and Place, 9(6), 517-530.

Kabeer, N. (1999). Resources, agency, achievements: Reflections on the measurement of women's empowerment. Development and Change, 30(3), 435-464.
Kabeer, N. (2001). Reflections on the measurement of women's empowerment. In: Discussing Women's EmpowermentTheory and Practice. Sida Studies No. 3. Stockholm: NovumGrafiska AB.

Kandel, W., \& Massey, D. S. (2002). The culture of Mexican migration: A theoretical and empirical analysis. Social forces, 80(3), 9811004.

Kelkar, G. (2007). The Feminization of Agriculture in Asia: Implications for Women's Agency and Productivity, Taipei: Food and Fertilizer Technology Center (FFTC), Retrieved from http://www.fftc.agnet.org/htmlarea_file/libr ary/20110725164020/eb594.pdf

Kelly, A. C., \& Williamson, J. G. (1984). What Drives Third World City Growth? A Dynamic General Equilibrium Approach. New York: The Princeton University Press.

Knodel, J., \& Saengtienchai, C. (2007). Rural parents with urban children: social and economic implications of migration for the rural elderly in Thailand. Population, Space and place, 13(3), 193-210.

Kothari, U. (2003). Introduction: migration, staying put and livelihoods. Journal of International Development, 15(5), 607-609.

Lastarria-Cornhiel, S. (2006). Feminization of agriculture: Trends and driving forces, Background Paper for the World Development Report 2008, Chile: RIMISP Latin American Center for Rural Development, Retrieved from http://siteresources.worldbank.org/INTWDR S/Resources/4773651327599046334/83946791327599874257/LastarriaCornhiel_Feminiza tionOfAgri.pdf

Lewis, W. A. (1954). Economic development with unlimited supplies of labour. The Manchester School, 22(2), 139-191.

Liu, J. (2014). Ageing, migration and familial support in rural China. Geoforum, 51, 305312. 
Lokshin, M., \&Glinskaya, E. (2009). The effect of male migration on employment patterns of women in Nepal. The World Bank Economic Review, 23(3), 481-507.

Maharjan, A., Bauer, S., \&Knerr, B. (2012). Do rural women who stay behind benefit from male out-migration? A case study in the hills of Nepal. Gender, Technology and Development, 16(1), 95-123.

Malhotra, A., \& Schuler, S. R. (2005).Women's empowerment as a variable in international development. (pp.71-88). In: Narayan, D. (Ed.). Measuring empowerment: Crossdisciplinary perspectives, Washington, D.C.: World Bank.

Massey, D. S., Arango, J., Hugo, G., Kouaouci, A., Pellegrino, A., \& Taylor, J. E. (1993). Theories of international migration: A review and appraisal. Population and development review, 431-466.

Mathew, G. (1995). New economic policies, social development and sociology. Sociological Bulletin, 44(1), 63-77.

McEvoy, J. P. (2008). Male out-migration and the women left behind: A case study of a small farming community in southeastern Mexico. ProQuest Dissertation Publishing, Utah State University.

Meng, X. (2014). Feminization of agricultural production in rural China: A sociological analysis. The Netherlands: Wageningen University.

Menjivar, C., \& Agadjanian, V. (2007). Men's migration and women's lives: Views from rural Armenia and Guatemala. Social Science Quarterly, 88(5), 1243-1267.

Mergo, T. (2016).The effects of international migration on migrant-source households: Evidence from Ethiopian diversity-visa lottery migrants. World Development, 84, 69-81.

Moghadam, V. M., \&Senftova, L. (2005). Measuring women's empowerment: participation and rights in civil, political, social, economic, and cultural domains.
International Social Science Journal, 57(184), 389-412.

Morokvasic, M. (2004).Migration, gender and empowerment (The Marie Jahoda-Decade: Gender Worlds in Change). Nov 2004, Bochum, Germany.

Mosse, D., Gupta, S., Mehta, M., Shah, V., Rees, J. F., \& Team, K. P. (2002). Brokered livelihoods: Debt, labour migration and development in tribal western India. Journal of Development Studies, 38(5), 59-88.

Mukharjee, S. S. (2013). Women's empowerment and gender bias in the birth and survival of girls in urban India. Feminist Economics, 19(1), 1-28.

Nguyen, L., Yeoh, B. S., \& Toyota, M. (2006). Migration and the well-being of the "left behind' in Asia: Key themes and trends. Asian Population Studies, 2(1), 37-44.

Parkins, N. (2010). Push and pull factors of migration. American Review of Political Economy, 8(2), 6-24.

Posel, D. (2001). How do households work? Migration, the household and remittance behaviour in South Africa. Social Dynamics, 27(1), 165-189.

Patel, M. R., Patel, A., Desai, J. D., Patel, V. B., \& Patel, N. R. (2016). Extent of variation caused by independent variables overall extent of contribution of tribal farmwomen in agricultural activities. Global Journal for Research Analysis, 5(6), 305-308.

Pattnaik, I., Lahiri-Dutt, K., Lockie, S., \& Pritchard, B. (2017). The feminization of agriculture or the feminization of agrarian distress? Tracking the trajectory of women in agriculture in India. Journal of the Asia Pacific Economy, 1-18. doi:10.1080/13547860.2017.1394569

Petticrew, M., \& Roberts, H. (2006).Systematic reviews in the social sciences: A practical guide. USA: Blackwell.

Pieke, F. N., \& Biao, X. (2009). Legality and labour: Chinese migration, neoliberalism and 
the state in the UK and China. Geopolitics, History and International Relations, 1(1), 11.

Plummer, R., Crona, B., Armitage, D. R., Olsson,P., Tengo, M., \&Yudina,O. (2012). Adaptive comanagement: A systematic review and analysis. Ecology and Society, 17(3), 11.http://dx.doi.org/10.5751/ES04952-170311

Radel, C., Schmook, B., \& McCandless, S. (2010). Environment, transnational labor migration, and gender: case studies from southern Yucatán, Mexico and Vermont, USA. Population and Environment, 32(2-3), 177-197.

Radel, C., Schmook, B., McEvoy, J., Mendez, C., \&Petrzelka, P. (2012). Labour migration and gendered agricultural relations: the feminization of agriculture in the Ejidal sector of Calakmul, Mexico. Journal of Agrarian Change, 12(1), 98-119.

Ranis, G., \&Fei, J. C. (1961).A theory of economic development. The American Economic Review, 51(4), 533-565.

Rao, N. (2006). Land rights, gender equality and household food security: Exploring the conceptual links in the case of India. Food Policy, 31(2), 180-193.

Ravenstein, E. G. (1885).The laws of migration. Journal of the statistical society of London, 48(2), 167-235.

Reddy, A. A., Rani, C., \& Reddy, G. P. (2015). Labour scarcity and farm mechanisation: A cross state comparison. Indian Journal of Agricultural Economics, 69(3), 347-358.

Rigg, J. (2007). Moving lives: migration and livelihoods in the Lao PDR. Population Space Place, 13(3), 163-178.

Rosewarne, S. (2010). Globalisation and the Commodification of Labour: Temporary Labour Migration. The Economic and Labour Relations Review, 20(2), 99-110.

Rowlands, J. (1995a). Empowerment examined. Development in Practice, 5(2), 101-107.

Rowlands, J. (1995b). Empowerment examined: an exploration of the concept and practice of women's empowerment in Honduras.

Doctoral thesis, Durham University.

Retrieved from:

(http://etheses.dur.ac.uk/1424/ )

Rowthorn, R. (2010). Combined and uneven development: Reflections on the NorthSouth divide. Spatial Economic Analysis, 5(4), 363-388

Roy, A., \& Nangia, P. (2005). Reproductive health status of wives left behind by male out-migrants: a study of rural Bihar, India. In S. Jatrana, M. Toyota, B. Yeoh (eds), Migration and Health in Asia (pp. 209-241). London: Routledge.

Roy, A., Singh, P., \& Roy, U. (2015). Impact of rural-urban labour migration on education of children: a case study of left behind and accompanied migrant children in India. Space and Culture, India, 2(4), 17-34. doi:10.20896/saci.v2i4.74

Sabates-Wheeler, R., \& Waite, M. (2003). Migration and social protection: A concept paper. Sussex: Institute of Development Studies, Retrieved from https://assets.publishing.service.gov.uk/me dia/57a08d2140f0b6497400167c/WP-T2.pdf

Sabur, M.A., \& Mahmud, H. (2009). Political impacts of remittances: A micro-level study of migrants' remittances in a village in Bangladesh. Asian Social Science, 4(12), 128134.

Sadiqi, F., \& Ennaji, M. (2004). The impact of male migration from Morocco to Europe on women a gender approach. Finisterra, 39(77), 59-76.

Sarker, Md. M., \& Islam, Md. S. (2014).Husbands' international labour migration and the change of wives' position among the left-behind in rural Bangladesh.Research on Humanities and Social Science, 4(16), 57-62.

Schulden, J. D., Painter,T. M., Song, B., Valverde, E., Borman, M. A., MonroeSpencer, K., Bautista, G., Saleheen, H., Voetsch, A. C., \&Heffelfinger, J. D. (2014). HIV testing histories and risk factors among 
migrants and recent immigrants who received rapid HIV testing from three community-based organizations. Journal of Immigrant Minority Health, 16(5), 798-810.

Shangquan, G. (2000). Economic globalization: trends, risks and risk prevention. Economic \& Social Affairs, CDP Background Paper, 1. Retrieved from: http://www.un.org/en/development/desa/p olicy/cdp/cdp_background_papers/bp2000_ 1.pdf

Sharma, J. R. (2008). Practices of male labor migration from the hills of Nepal to India in development discourses: Which pathology? Gender, Technology and Development, 12(3), 303-323.

Singh, N. P., Singh, R. P., Kumar, R., Padaria, R. N., Singh, A., \& Varghese, N. (2011). Labour migration in Indo-Gangetic plains:

Determinants and impacts on socioeconomic welfare. Agricultural Economics Research Review, 24, 449-458.

Sinha, B., Jha, S., \& Negi, N. S. (2012). Migration and empowerment: The experience of women in households in India where migration of a husband has occurred. Journal of Gender Studies, 21(1), 61-76.

Singh, S. (2014). Women, environment and sustainable development: A case study of Khul Gad micro watershed of Kumoun Himalaya. Space and Culture, India, 1(3), 5364,doi:10.20896/saci.v1i3.45

Singh, S. (2015). Women as milieu managers in integrated watershed management: Perspectives from the hilly areas of Uttarakhand. Space and Culture, India, 2(4), 71-79, doi:10.20896/saci.v2i4.130

Southiseng, N., \& Walsh, J. (2011). Remittances and the changing roles of women in Laos, International Journal of Social, Behavioral, Educational, Economic, Business and Industrial Engineering, 5(1), 24-30.

Stark, O., \& Levhari, D. (1982). On migration and risk in LDCs. Economic development and cultural change, 31(1), 191-196.
Tamang, S., Paudel, K. P., \& Shrestha, K. K. (2014).Feminization of agriculture and its implications for food security in rural Nepal. Journal of Forest and Livelihood, 12(1), 20-32.

Thorne, S., Jensen, L., Kearney, M. H., Noblit, G., \&Sandelowski, M. (2004). Qualitative metasynthesis: Reflections on methodological orientation and ideological agenda. Qualitative Health Research, 14(10), 1342-1365.

Toyota, M., Yeoh, B. S., \& Nguyen, L. (2007). Bringing the 'left behind' back into view in Asia: a framework for understanding the 'migration-left behind nexus'. Population, Space and Place, 13(3), 157-161.

United Nations. (1995). Report of the World Summit for Social Development, Retrieved from: https://www.un.org/documents/ga/conf166 /aconf166-9.htm

Wang, T., Maruayama, A., \& Kikuchi, M. (2005). Rural-urban migration and labourmarket in China: a case study in a Northeastern province. The Developing Economies. 37(1), 80-104.

World Bank, FAO \& IFAD.(2009). Gender in agriculture sourcebook. Washington, DC. World Bank.

Yabiku, S.T., Agadjanian, V., \&Sevoyan, A. (2010).Husbands' labour migration and wives' autonomy, Mozambique 20002006.Population Studies, 64(3), 293-306.

Ye, J., Wang,C., Wu,H., He, C. ,\& Liu, J. (2013). Internal migration and left-behind populations in China. Journal of Peasant Studies, 40(6), 1119-1146.

Yeoh, B. S. A., Huang, S., \&Lam,T. (2005). Transnationalizing the 'Asian' family: Imaginaries, intimacies and strategic intents. Global Networks, 5(4), 307-315.

Zhou, C., Sylvia,S., Zhang,L., Luo, R., Yi,H., Liu,C., \&Rozelle,S. (2015). China's left-behind children: impact of parental migration on health, nutrition, and educational outcomes. Health Affairs, 34(11), 1964-1971. 


\section{About the Authors}

Shatabdi Saha is a doctoral student at the Integrated Rural Development and Management Faculty Centre of Ramakrishna Mission Vivekananda Educational and Research Institute. She is working with Rupak Goswami on migration left-behind nexus in Indian Sundarbans. Ms Saha has academic training in both Rural Development and Social Work and she has also worked on the broader issues of women and child health while working in the voluntary sector. Dr. Goswami is trained in Agricultural Sciences and is working on diverse issues related to the socio-economics of agriculture. Sujit Kumar Paul is serving at VisvaBharati University and has vast experience in the field of rural development and gender issues. The authors are now trying to understand the nexus of migration, feminised agriculture and women empowerment in Indian Sundarbans. 